\title{
The Synthetic Cannabinoid WIN 55,212-2 Elicits Death in Human Cancer Cell Lines
}

\author{
LEONIE MÜLLER $^{1,2}$, ARLO RADTKE $^{1}$, JENNIFER DECKER $^{1,2}$, MICHAEL KOCH $^{2}$ and GAZANFER BELGE ${ }^{1}$ \\ ${ }^{1}$ Faculty of Biology and Chemistry, and ${ }^{2}$ Department of Neuropharmacology- \\ Brain Research Institute, University of Bremen, Bremen, Germany
}

\begin{abstract}
Background: Studies have revealed that cancer might be treated with cannabinoids since they can influence cancer cell survival. These findings suggest an alternative treatment option to chemo- and radiotherapy, that are associated with numerous adverse side-effects for the patients. Materials and Methods: Viability staining was conducted on lung cancer, testicular cancer and neuroblastoma cells treated with different concentrations of the synthetic cannabinoid WIN 55,212-2 and the percentage of dead cells was compared. Activity of apoptosis-related enzymes was investigated by the presence of DNA ladder in gel electrophoresis. Results: Treatment with different WIN 55,212-2 concentrations led to a significant dose-dependent reduction of cell viability. A DNA ladder was observed after WIN 55,212-2 treatment of testicular cancer and lung cancer cells. Conclusion: The application of WIN 55,212-2 was found to trigger cell death in the investigated cell lines. The decline in lung cancer and testicular cancer cell viability seems to have been caused by apoptosis. These findings may contribute to development of alternative cancer therapy strategies.
\end{abstract}

In today's research, there is an increasing interest in the curative properties of cannabinoids. Since the discovery of the endocannabinoid system, a better understanding of the function of endocannabinoids on the cellular level has been established. In nerve cells, endocannabinoids are synthesized post-synaptically and act at the presynapse via cannabinoid Gi-coupled receptors (CBRs), thereby regulating a variety of cellular processes (1). Beside endocannabinoids, there are known 70 cannabinoids of the hemp plant Cannabis sativa L. (2). In addition, there are several synthetic cannabinoids

Correspondence to: Gazanfer Belge, Faculty of Biology and Chemistry, University of Bremen, Leobener Straße 2, 28359 Bremen, Germany. Tel: +49 42121861570,e-mail: belge@unibremen.de

Key Words: WIN 55,212-2, lung cancer, testicular cancer, neuroblastoma, apoptosis. available. One of them is the $\mathrm{CB} 1$ and $\mathrm{CB} 2$ receptor agonist $(R)-(+)$-WIN 55,212-2 mesylate salt (WIN) (3). An improvement of symptoms after intake of cannabinoids was reported for several diseases. For instance, they can be used to treat psychotic symptoms (4), epilepsy (5) and spasticity as a symptom of multiple sclerosis (6). Additionally, the successful treatment of pain was reported (7). Cannabinoids are also important for the treatment of patients with cancer. They can be useful during the therapy of patients who suffer from anorexia as a consequence of chemotherapy for cancer because cannabinoids have orexogenic as well as analgesic effects, and reduce nausea (8). Furthermore, they can modulate several properties, for instance adhesion, invasion, migration and metastasis of cancer cells, as wells as tumor neovascularization (9). Moreover, cannabinoids have the potential to influence cancer cell survival directly. Beside the inhibition of tumor cell proliferation the induction of apoptosis was observed in some cell types by several working groups. Beneficial effects were demonstrated in breast, skin, pancreatic, bone, oral, thyroid, prostate and lung cancer, lymphomas and gliomas after application of different cannabinoids (10-12). However, it is not possible to clearly summarize the effects of cannabinoids on cancer cells, due to a lack of functional understanding at the cellular level.

Cancer is a severe disease that still causes many deaths every year. Therefore, it is important to conduct further research in this area because besides radio- and chemotherapy, which have severe side-effects $(13,14)$, there are practically no other known alternative treatment options.

In this study, the effect of the synthetic cannabinoid WIN on the cell viability of different cancer cell lines was investigated. Beside the A549 lung cancer cell line, a newly established testis tumor cell line, HoTu-10, and the neuroblastoma cell line IMR-5 were investigated. In particular, lung cancer leads to many deaths in Germany, where it is the most frequent cancer-related cause of death in males, while it is ranked third in females (15). Testicular tumors are relatively curable but are common neoplasia in younger men aged between 15-39 years (16). For such young patients who are often well into their reproductive phase, 
radio- and chemotherapy treatment are a burden due to their risk of inducing infertility. Thus, alternative cancer therapy approaches for these patients are desirable. Therefore, the cell viability and the induction of apoptosis after application of the synthetic cannabinoid WIN were investigated in lung cancer, testicular cancer and neuroblastoma cell lines.

\section{Materials and Methods}

Cell culture and treatment. The A549 lung carcinoma cell line (Cell Line Services, Eppelheim, Germany) and the HoTu-10 testicular non-seminomatous germ cell cancer cell line (established by G. Belge, University of Bremen, Germany) were cultured in TC 199 medium with Earle's salts supplemented with $20 \%$ fetal bovine serum, $200 \mathrm{IU} / \mathrm{ml}$ penicillin and $200 \mu \mathrm{g} / \mathrm{ml}$ streptomycin. The IMR5 neuroblastoma cell line (Cell Line Services) was cultured in RPMI 1640 medium with Earle's salts supplemented with $10 \%$ fetal bovine serum, $200 \mathrm{IU} / \mathrm{ml}$ penicillin and $200 \mu \mathrm{g} / \mathrm{ml}$ streptomycin. All cells were incubated at $37^{\circ} \mathrm{C}$ in an atmosphere of $5 \% \mathrm{CO}_{2}$. For cell viability staining and DNA isolation, confluent cells were trypsinized (trypsin/EDTA solution $0.05 \% / 0.02 \%$ w/v $\mathrm{Ca}^{2+}$; Biochrom, Berlin, Germany) and plated onto 6-well-plates (coverslips) and incubated in their respective culture medium.

Cell growth curve and toxicity test. Cells of each cell line were cultured and counted at $24 \mathrm{~h}$ intervals for 7-day period. The information about the growth behavior, especially the point of ideal cell growth was necessary for treatment of the cells with the synthetic cannabinoid WIN (Sigma-Aldrich, Munich, Germany). In order to determine the optimal solvent for WIN application, a solvent toxicity test was performed. Each cell line was cultured on a 12 well-plate. The wells were treated either with ethanol (70\%), $\mathrm{HCl}(0.1 \%)$ or Tween $80(0.1 \%)$. Ethanol led to the lowest cytotoxicity and was accordingly used as a solvent for the WIN during the experiments.

Trypan blue cell viability staining. The cells were seeded on 12-wellplates at $15 \times 10^{4}$ cells/well. WIN was applied when the cells were confluent: the medium was removed and new medium with final WIN concentration of 5,10 or $20 \mu \mathrm{M}$ was added to the cells. Cells treated with the same amount of ethanol were used as controls. Therefore, the amount of used medium, WIN and ethanol for the specific WIN concentration was equal for each respective well and plate. Subsequently, the treated cells were incubated at $37^{\circ} \mathrm{C}$ and with $5 \%$ $\mathrm{CO}_{2}$ for $48 \mathrm{~h}$ for the cell viability test. Afterwards, for trypan blue staining process, the medium of each well was removed, cell layers were washed with phosphate-buffered saline (PBS) (Biochrom, Berlin, Germany) and trypsinized. The detached cells of each well were resuspended and centrifuged for $10 \mathrm{~min}$ at $100 \times \mathrm{g}$. The pellets were dissolved in $400 \mu \mathrm{l}$ PBS and $200 \mu \mathrm{l}$ trypan blue $(0.4 \%$, SigmaAldrich, Munich, Germany) was added. This solution was incubated at room temperature for $5 \mathrm{~min}$. Finally, the dyed cells were counted in a microscope using a hemocytometer.

DNA isolation and laddering verification. For the verification of apoptosis by detection of DNA laddering, cells were seeded on 6 well plates at $2 \times 10^{5}$ cells/well. The cells were treated with $20 \mu \mathrm{M}$ WIN for $72 \mathrm{~h}$ at $37^{\circ} \mathrm{C}$ and in $5 \% \mathrm{CO}_{2}$ and afterwards dissociated by use of trypsin as above. All wells of the plate treated with the same
WIN concentration were transferred to a centrifuge tube and all control wells were transferred to another. Thereupon, the cell DNA was isolated using QIAMP DNA mini kit (QIAGEN, Hilden, Germany) according to the manufacturer's instructions. Subsequently, the concentration of DNA samples was then measured in a biophotometer (Eppendorf, Hamburg, Germany). Gel electrophoresis was performed with $2 \%$ agarose gel with $4 \mu \mathrm{g}$ ethidium bromide and $1 \mu \mathrm{g}$ to $6 \mu \mathrm{g}$ DNA sample. The amount of DNA used was equal for samples treated with WIN and samples treated with ethanol. Moreover, $1 \mathrm{~kb}$ DNA Ladder Plus (Thermo Fisher Scientific, Schwerte, Germany) was applied to at least one slot of the gel. Agarose gel electrophoresis was performed for 120 min at $90 \mathrm{~V}$. The gel was imaged using a gel documentation system and edited with ArgusX1 software (Biostep, Burkhardtsdorf, Germany)

Statistical analysis. Data are presented either as mean \pm standard deviation or as median with interquartile range. The two-sided Mann-Whitney $U$-test was employed to detect differences between subgroups. A significant difference was assumed at values of $p<0.05$. The statistical analysis was carried out with SPSS v24 (IBM, Armonk, NY, USA).

\section{Results}

The A549, HoTu-10 and IMR-5 cells were treated with $5 \mu \mathrm{M}$, $10 \mu \mathrm{M}$ and $20 \mu \mathrm{M}$ of WIN, as well as with ethanol as a control. In all three cell lines, the controls displayed the lowest amount of cell death, while higher concentrations of WIN caused more cells to die in a dose-dependent manner, except for IMR-5 cells treated with $5 \mu \mathrm{M}$ WIN, which displayed a higher percentage of dead cells than the cells treated with $10 \mu \mathrm{M}$ WIN (Figure 1).

For statistical analysis, the sample number was increased (Figure 2). Treatment with $10 \mu \mathrm{M}$ WIN resulted in significantly more dead cells for all three cell lines $(p<0.0001$ each) compared to the controls. In HoTu-10 and IMR-5 cells, the difference was also significant between controls and cells treated with $20 \mu \mathrm{M}$ WIN (both $p<0.0001$ ), and between $10 \mu \mathrm{M}$ and $20 \mu \mathrm{M}$ WIN-treated cells $(p=0.004$ for HoTu-10 and $p=0.02$ for IMR-5).

Treatment with $20 \mu \mathrm{M}$ WIN caused a decay of genomic DNA into fragments of approximately 180 base pairs length in A549 and HoTu-10 cells (Figure 3). This DNA laddering was only visible using high DNA amounts $(6 \mu \mathrm{g})$ and was neither observed in the A549 or HoTu-10 controls, nor in the IMR-5 cells treated with $20 \mu \mathrm{M}$ of WIN.

\section{Discussion}

Cannabinoids are known to influence several cellular processes in tumor cell lines of various cancer types. One promising observation is the induction of cancer cell death. This effect on cell survival might be useful to introduce an alternative treatment for patients with cancer. There are several studies concerning the effects of cannabinoids on the 


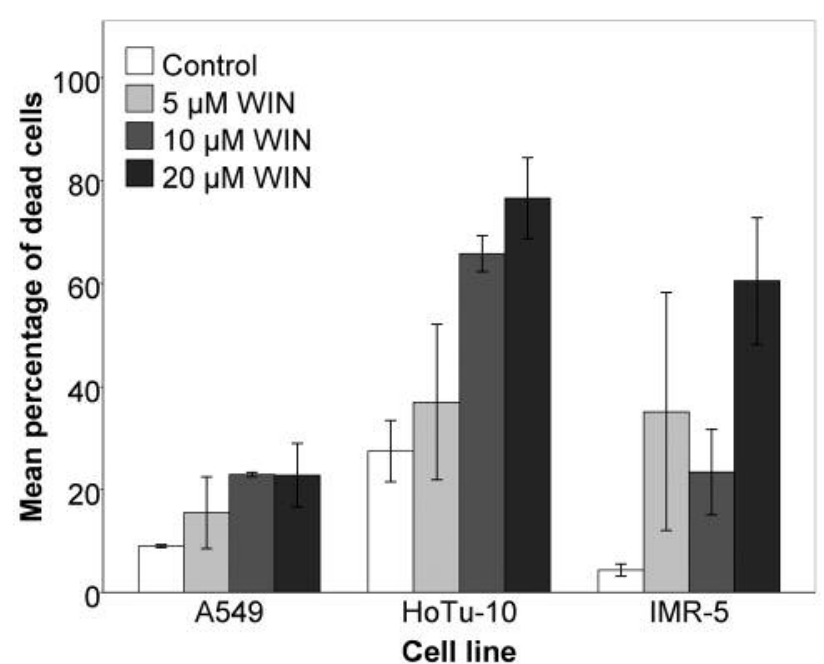

Figure 1. Percentage of dead cells after treatment of A549, HoTu-10 and IMR-5 cells with different doses of $(R)-(+)-W I N$ 55,212-2 mesylate salt $($ WIN). Data are the mean \pm standard deviation $(n=3)$.

A549 lung cancer cell line. For example, $\Delta 9$-tetrahydrocannabinol (THC) inhibited the migration of A549 cells (17). Moreover, WIN, and the CBR agonist JWH-133 reduced the size of lung metastases in vivo (18). Furthermore, cannabidiol was shown to reduce cell viability of A549 associated with apoptosis (19). Exposure to THC also reduced cell viability of A549 lung cancer cells (20). Effects of cannabinoids on testicular cancer cell lines have not been described before. For neuroblastoma cell lines, there are few investigations concerning the effects of cannabinoids. Apoptotic effects and a decrease in cell viability in vitro in neurons and neuroblastoma cell lines after the addition of different cannabinoids were reported (21). However, the effect of the mixed CBR agonist WIN on the IMR-5 neuroblastoma cell line had not previously been investigated.

Here, we demonstrate for the first time a dose-dependent reduction of the viability of the A549 lung cancer cell line, the HoTu-10 testicular cancer cell line and the IMR-5 neuroblastoma cell line after administration of different concentrations of WIN. For an initial exploration of efficient doses, several concentrations that were reported to be effective against other cell lines were applied to these cells. Even though the sample size was small, a dose-dependent effect was observed. An increase in the mean percentage of cell death was found for increasing WIN concentrations in all cell lines. Two exceptions were observed. Firstly, no increase in cell death was reported from $10 \mu \mathrm{M}$ to $20 \mu \mathrm{M}$ WIN-treated A549 cells. Likewise, Sarafian and colleagues were unable to detect a decrease in A549 cell viability when treating these cells with similar concentrations of the phytocannabinoid

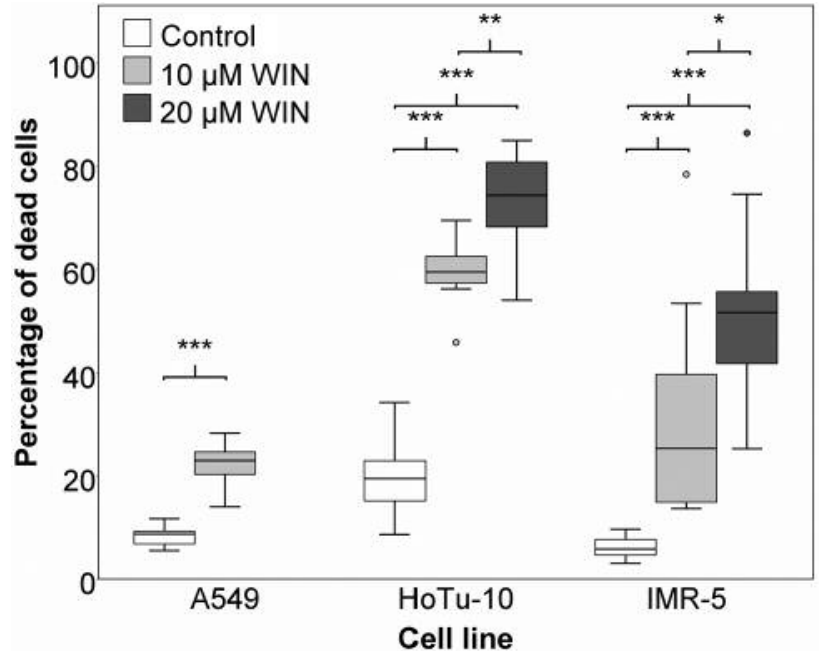

Figure 2. Boxplots of the percentage of dead A549, HoTu-10 or IMR-5 cells after treatment with $(R)-(+)-W I N$ 55,212-2 mesylate salt (WIN). All $n=9$, except $n=10$ for HoTu-10 cells at $20 \mu \mathrm{M}$ concentration and $n=11$ for IMR-5 cells at $10 \mu \mathrm{M}$. Significant differences between subgroups at $* p<0.05 ; * * p<0.01 ; * * * p<0.001$.

THC (20). This suggests that an increase in cannabinoid concentration from $10 \mu \mathrm{M}$ to $20 \mu \mathrm{M}$ has little effect on A549 cell viability. Secondly, more of the IMR-5 cells treated with $5 \mu \mathrm{M}$ WIN died compared to cells treated with $10 \mu \mathrm{M}$ WIN. This might be due to the fact that the large standard deviation shows the mean could not be reliable calculated out of three samples for the $5 \mu \mathrm{M}$ WIN concentration. To further investigate the suggested dose-dependent effects, treatment with 10 and $20 \mu \mathrm{M}$ WIN was repeated to obtain a larger sample size. This resulted in significantly more dead A549 cells after application of $10 \mu \mathrm{M}$ WIN in comparison to the control group. Moreover, it was described for the first time that the application of WIN to the HoTu-10 and IMR-5 cell lines revealed a significant effect on their cell viability. While the mean percentage of cell death increased after $10 \mu \mathrm{M}$ WIN treatment in comparison to the control, the effect was even greater when the cells were treated with $20 \mu \mathrm{M}$ WIN.

We then carried out further investigations to identify which signaling pathways were involved in the WIN-induced death of the cells. Traditionally, two major principles of cell death, necrosis and apoptosis, can be distinguished. While necrosis is characterized as unregulated cell death, apoptosis is commonly considered as programmed cell death (22). Sarfaraz et al. suggested that the decline in cell viability of LNCaP prostate cancer cells after WIN application was associated to the induction of apoptosis (23). In this study, the mechanism of cell death in the cell lines was assessed by DNA fragmentation after addition of WIN. Normally, the induction of apoptosis would lead to caspase- 3 activation 


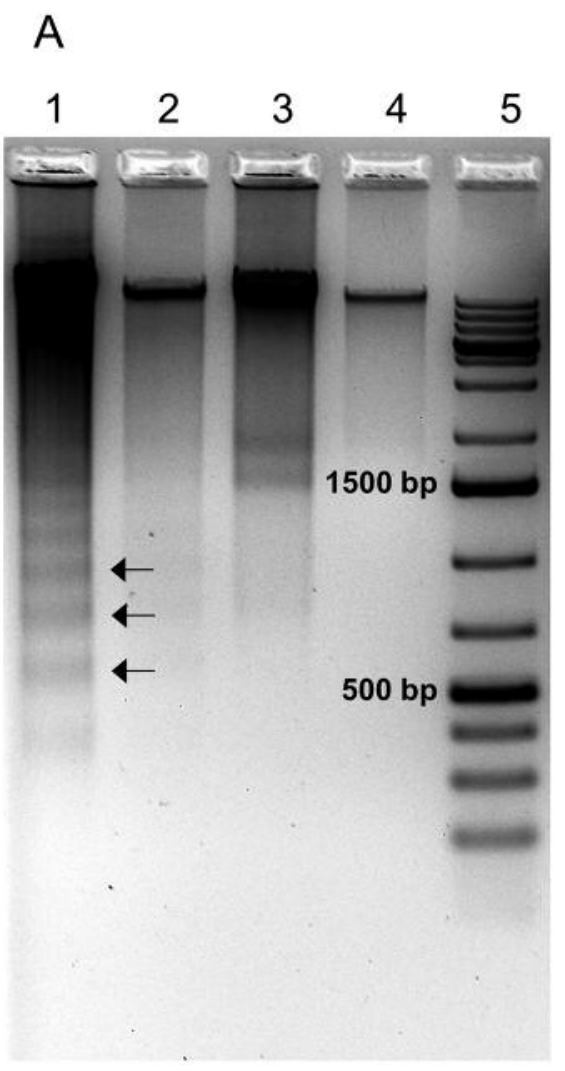

B

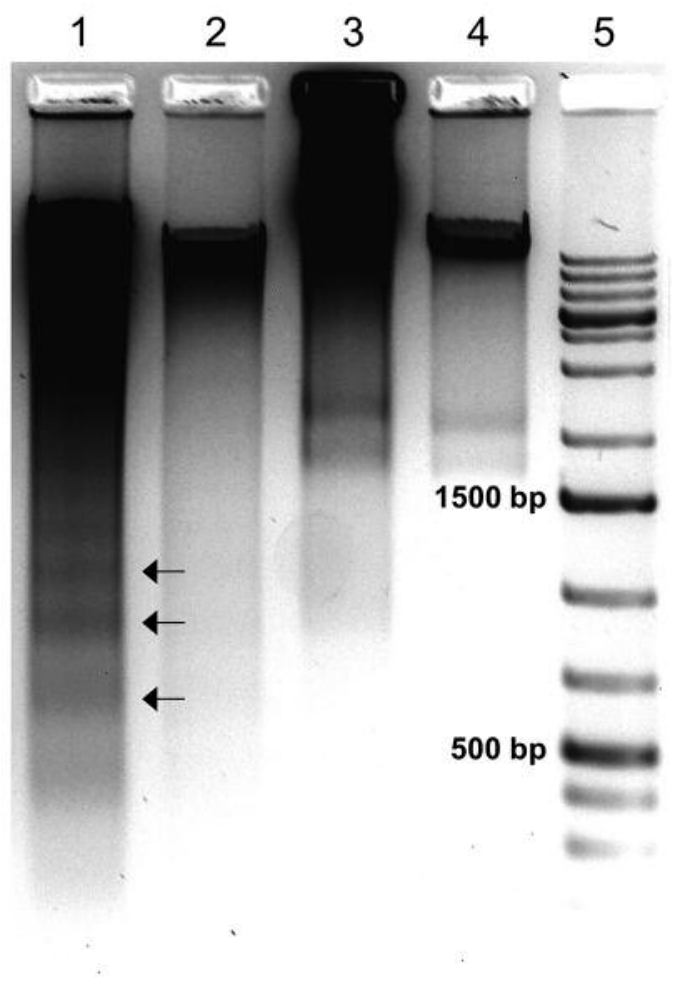

Figure 3. Agarose gel electrophoresis of DNA from A549 (A) and HoTu-10 (B) cells treated with $20 \mu M(R)-(+)$-WIN 55,212-2 mesylate salt (WIN) and the according controls. In both parts, $6 \mu \mathrm{g}$ DNA from treated cells (lane 1), $1 \mu \mathrm{g}$ DNA from treated cells (lane 2), $6 \mu \mathrm{g}$ DNA from control cells (lane 3), 1 g D DNA from control cells (lane 4) and a molecular weight marker (lane 5) were used. Arrows indicate the ladder pattern. No DNAladder pattern was visible on treatment of I MR-5 cells with WIN (data not shown).

which cleaves the inhibitor of caspase-activated DNase (CAD) from CAD. Consequently, CAD is activated and cuts DNA into fragments of multiples of 180 base pairs (24). Such a pattern of DNA fragments is a characteristic hallmark of apoptosis. DNA fragments with a length of 180 base pairs and multiples thereof were detected in A549 and HoTu-10 DNA. This suggests that the observed decline in cell viability after WIN treatment can be explained by the induction of apoptosis. Nevertheless, this ladder structure was not observed after WIN treatment of IMR- 5 cells. This might be due to the fact that this cell type did not show CAD activity during apoptosis as Yuste et al. already reported (25). However, this does not exclude the possibility that apoptosis is also induced in this cell line after exposure to WIN. Therefore, the underlying mechanism that led to the decline in cell viability in IMR-5 cells remains unclear and needs to be investigated. For A549 and HoTu-10 cells, apoptosis seems to be involved in the WIN-induced reduction of cancer cell viability.
To summarize, cannabinoids can restrict the survival of various cell types in vitro. Moreover, for some cancer types the efficiency of cannabinoids was already proven in in vivo models, indicating possible future application in cancer therapy. Here we demonstrated that treatment with the synthetic CBR mixed agonist WIN results in death of lung cancer, testicular tumor and neuroblastoma cells. Furthermore, apoptosis was confirmed as the mechanism of cell death in lung and testicular tumor cells. Further research should clarify the underlying mechanisms of cell death in the IMR-5 cell line. Overall it can be concluded that lung cancer, testicular cancer and neuroblastoma can be added to the growing list of tumors susceptible to cannabinoid therapy.

\section{Conflicts of Interest}

All Authors declare that there are no conflicts of interest in regard to this study. 


\section{References}

$1 \mathrm{Lu} \mathrm{H}-\mathrm{C}$ and Mackie $\mathrm{K}$ : An introduction to the endogenous cannabinoid system. Biol Psychiatry 79: 516-525, 2016.

2 ElSohly MA and Slade D: Chemical constituents of marijuana: the complex mixture of natural cannabinoids. Life Sci 78: 539$548,2005$.

3 Alexander SPH: Therapeutic potential of cannabis-related drugs. Prog Neuropsychopharmacol Biol Psychiatry 64: 157-166, 2016.

4 Iseger TA and Bossong MG: A systematic review of the antipsychotic properties of cannabidiol in humans. Schizophr Res 162: 153-161, 2015.

5 Russo EB: Cannabis and epilepsy: An ancient treatment returns to the fore. Epilepsy Behav 70: 292-297, 2017.

6 Baker D, Pryce G, Croxford JL, Brown P, Pertwee RG, Huffman JW and Layward L: Cannabinoids control spasticity and tremor in a multiple sclerosis model. Nature 404: 84-87, 2000.

7 Burston JJ and Woodhams SG: Endocannabinoid system and pain: an introduction. Proc Nutr Soc 73: 106-117, 2014.

8 Limebeer CL, Rock EM, Mechoulam R and Parker LA: The anti-nausea effects of $\mathrm{CB} 1$ agonists are mediated by an action at the visceral insular cortex. Br J Pharmacol 167: 1126-1136, 2012.

9 Freimuth N, Ramer R and Hinz B: Antitumorigenic effects of cannabinoids beyond apoptosis. J Pharmacol Exp Ther 332: 336344, 2010.

10 Cridge BJ and Rosengren RJ: Critical appraisal of the potential use of cannabinoids in cancer management. Cancer Manag Res 5: 301-313, 2013.

11 Chakravarti B, Ravi J and Ganju RK: Cannabinoids as therapeutic agents in cancer: current status and future implications. Oncotarget 5: 5852-5872, 2014.

12 Nikan M, Nabavi SM and Manayi A: Ligands for cannabinoid receptors, promising anticancer agents. Life Sci 146: 124-130, 2016.

13 Davis MP: Oral nabilone capsules in the treatment of chemotherapy-induced nausea and vomiting and pain. Expert Opin Investig Drugs 17: 85-95, 2008.

14 Duran M, Pérez E, Abanades S, Vidal X, Saura C, Majem M, Arriola E, Rabanal M, Pastor A, Farré M, Rams N, Laporte J-R, Capellà D: Preliminary efficacy and safety of an oromucosal standardized cannabis extract in chemotherapy-induced nausea and vomiting. Br J Clin Pharmacol 70: 656-663, 2010.

15 Blum T, Schönfeld N, Kollmeier J, Ammenwerth W, Grüning W, Nehls W and Bauer TT: Lung cancer in Germany - the current state of management. Pneumologie 65: 7-18, 2011.
16 Ferlay J, Soerjomataram I, Dikshit R, Eser S, Mathers C, Rebelo M, Parkin DM, Forman D and Bray F: Cancer incidence and mortality worldwide: Sources, methods and major patterns in GLOBOCAN 2012. Int J Cancer 136: 359-386, 2015.

17 Preet A, Ganju RK and Groopman JE: $\Delta$ 9-Tetrahydrocannabinol inhibits epithelial growth factor-induced lung cancer cell migration in vitro as well as its growth and metastasis in vivo. Oncogene 27: 339-346, 2008.

18 Qamri Z, Preet A, Nasser MW, Bass CE, Leone G, Barsky SH and Ganju RK: Synthetic cannabinoid receptor agonists inhibit tumor growth and metastasis of breast cancer. Mol Cancer Ther 8: 3117-3129, 2009.

19 Ramer R, Heinemann K, Merkord J, Rohde H, Salamon A, Linnebacher $M$ and Hinz B: COX-2 and PPAR- $\gamma$ confer cannabidiol-induced apoptosis of human lung cancer cells. Mol Cancer Ther 12: 69-82, 2013.

20 Sarafian TA, Kouyoumjian S, Khoshaghideh F, Tashkin DP and Roth MD: $\Delta$ 9-tetrahydrocannabinol disrupts mitochondrial function and cell energetics. Am J Physiol Lung Cell Mol Physiol 284: 298-306, 2003.

21 Guzmán M, Sánchez C and Galve-Roperh I: Cannabinoids and cell fate. Pharmacol Therapeut 95: 175-184, 2002.

22 Martin SJ and Henry CM: Distinguishing between apoptosis, necrosis, necroptosis and other cell death modalities. Methods 61: 87-89, 2013.

23 Sarfaraz S, Afaq F, Adhami VM, Malik A and Mukhtar H: Cannabinoid receptor agonist-induced apoptosis of human prostate cancer cells $\mathrm{LNCaP}$ proceeds through sustained activation of ERK1/2 leading to G1 cell cycle arrest. J Biol Chem 281: 39480-39491, 2006.

24 Hengartner MO: The biochemistry of apoptosis. Nature 407: 770-776, 2000.

25 Yuste VJ, Bayascas JR, Llecha N, Sánchez-López I, Boix J and Comella JX: The absence of oligonucleosomal DNA fragmentation during apoptosis of IMR-5 neuroblastoma cells: disappearance of the caspase-activated DNase. J Biol Chem 276: 22323-22331, 2001.
Received August 9, 2017

Revised September 29, 2017

Accepted October 3, 2017 